This item was submitted to Loughborough's Research Repository by the author.

Items in Figshare are protected by copyright, with all rights reserved, unless otherwise indicated.

\title{
Leverage constraints and real interest rates
}

PLEASE CITE THE PUBLISHED VERSION

http://dx.doi.org/10.1111/manc.12111

\section{PUBLISHER}

(c) The University of Manchester and John Wiley \& Sons Ltd

\section{VERSION}

AM (Accepted Manuscript)

\section{PUBLISHER STATEMENT}

This work is made available according to the conditions of the Creative Commons Attribution-NonCommercialNoDerivatives 4.0 International (CC BY-NC-ND 4.0) licence. Full details of this licence are available at: https://creativecommons.org/licenses/by-nc-nd/4.0/

\section{LICENCE}

CC BY-NC-ND 4.0

\section{REPOSITORY RECORD}

Isohaetaelae, Jukka, F.V. Kusmartsev, Alistair Milne, and Donald Robertson. 2019. "Leverage Constraints and Real Interest Rates". figshare. https://hdl.handle.net/2134/20546. 


\title{
Leverage constraints and real interest rates*
}

\author{
Jukka Isohätälä**, Feo Kusmartsev ${ }^{* *}$, Alistair Milne ${ }^{\dagger}$, and Donald Robertson ${ }^{\dagger \dagger}$ \\ March 27, 2015
}

\begin{abstract}
This paper investigates the macroeconomic dynamics of consumption and real interest rates when there are constraints on debt finance, used both for insurance against income shocks and transferability of resources over time. We amend a standard continuous-time deterministic model, with patient and impatient household sectors, introducing sector level income shocks. Shocks that push the impatient sector towards its leverage limit increase precautionary saving and result in a substantial but transient decline of the real interest rate relative to the deterministic benchmark. We discuss the resulting dynamics of consumption, leverage and interest rates and implications for macroeconomic modelling and policy. [100 words]
\end{abstract}

Journal of Economic Literature number: E44

Keywords: borrowing constraints, debt management, incomplete financial markets, international macroeconomics, finance and macroeconomics, leverage cycles, macroeconomic propagation, precautionary saving, secular stagnation, systemic risk

** Department of Physics, Loughborough University, Loughborough, UK

$\dagger$ Corresponding author, School of Business and Economics, Loughborough University, Epinal Way, Loughborough LE11 3TU, UK, email: a.k.l.milne@lboro.ac.uk $\ddagger$ Faculty of Economics, University of Cambridge, Cambridge, UK

${ }^{*}$ We thank the Bank of England research donations committee for providing seed corn funding for this research. We are grateful for comments from two anonymous reviewers, Luis Alvarez, Jean-Charles Rochet and from audiences at the Sept 2014 Money, Macro and Finance conference, the Bank of England, the Bank of Finland, the October 2013 ESRC Seminar on financial modelling post-2008 at Manchester University, the Institute of Banking and Finance at Zurich University and the University of Lund. The views expressed here are our own and not necessarily those of the Bank of England or any other organisation. 


\section{$1 \quad$ Introduction}

The economics profession lacks standard models of the impact of debt accumulation on the behaviour of key macroeconomic variables, such as interest rates and consumption. This paper takes a small step towards filling this gap, developing a model of the dynamic response of an exchange economy to income shocks in an incomplete market setting. Introducing constraints on leverage we are able to capture, in a modern modelling framework, a dependence of real interest rates on sectoral balance sheets driven by precautionary saving. This allows us to address questions, neglected in recent literature, about the relationship between aggregate leverage, consumption and real interest rates.

This modelling exercise is motivated by the combination of growing debt to income ratios and falling short term real interest rates of the past third of a century. This growth in debt is highlighted by the recent Geneva report on the global economy (Buttiglione et al. [2014]). Their Figure 4.1 shows that the ratio of US non-financial debt to income nearly doubled over twenty five years, from approximately $125 \%$ of GDP in 1981 to $240 \%$ of GDP in 2009 (in the aftermath of the global financial crisis) and has remained at this high level over the subsequent five years. Globally (their Figure 1.1) non-financial debt to income ratios climbed from $165 \%$ of GDP in 2001 and continued to rise after the global financial crisis to reach $210 \%$ of GDP in 2013.

Over the same period global three month real interest rates have fallen markedly, from a peak of over 5\% in 1982 to $-2 \%$ in 2013 (IMF [2014]) Figure 3.2)).1 (Blanchard et al. [2014] $)$ discuss three explanations of this decline in the natural or equilibrium real rate of interest: higher global savings,

\footnotetext{
${ }^{1}$ according to this same measure real short term rates were also negative during the $1970 \mathrm{~s}$, in the range $-1 \%$ to $-3 \%$
} 
lower investment and a shift in portfolio preferences from riskier to safer assets. While referring to possible increases in precautionary saving because of greater income uncertainty, they do not mention the mechanism that emerges in our modelling where higher sectoral leverage increases precautionary saving and reduces real interest rates.

Our model has two sectors: a leveraged borrowing sector and a lending sector that owns the debt claims issued by the borrowing sector. This allows us to embed precautionary saving of the kind familiar from standard microeconomic literature in a general macroeconomic equilibrium, yielding simple and intuitive if somewhat counterfactual predictions. In our model the optimal choices of consumption mean that shocks that increase leverage result in declines in real interest rates that reduce the burden of debt repayment on the borrowing sector. This decline of real interest rates, together with relatively modest reductions of consumption, is the mechanism through which the borrowing sector 'deleverages', reducing the ratio of debt to income towards a desired target level.

In the interests of tractability we impose some strong modelling assumptions. Decision making in each of the two sectors is captured by a single infinitely lived representative agent with preferences represented by a standard discounted expected utility function. The model is though intended to capture the behaviour of large number of atomistic households within each sector, so the representative agents take no account of the impact of altering consumption on the real real rate of interest (households are price takers). Time is continuous and there is a single non-storable good that may be costlessly exchanged between the sectors. The model is non-monetary with the real interest rate adjusting instantaneously to ensure goods market equilibrium. Expected output of each sector is a constant (i.e. this is a pure 
exchange economy with no capital accumulation or labour input).

Following the example of Clarida [1990 we incorporate heterogeneity by assuming that agents have different time discount rates, relatively high in the impatient (borrowing) sector and relatively low in the patient (lending) sector. Shocks are increments to a diffusion process that directly raise the output of one sector and correspondingly reduce the output of the other sector. Shocks to income are uninsurable (our incomplete market assumption). Borrowing is subject to an exogenous leverage constraint. Real interest rates adjust instantaneously to achieve goods market clearing (so in this model there is no role for money or monetary policy).

In this setting the consumption decisions of the borrowing sector are the outcome of two conflicting incentives: the desire to consume earlier rather than later in time; and the desire to save in order to reduce debt and so be better able to manage future income fluctuations. The lending sector in contrast always seeks to consume later rather than earlier. Net savings are further affected by the income effects of (temporary) interest rate fluctuations. When interest rates are comparatively low this raises the income and savings of the borrowing sector and lowers the income and savings of the lending sector.

The outcome is a general equilibrium 'buffer stock' model, much like that which emerges from standard microeconomic models of precautionary saving by individual households. The impatient borrowing sector seeks to move towards a target or buffer leverage ratio; but with the nuance that fluctuations of interest rates take place to ensure a mutually consistent general equilibrium outcome so that when leverage is high interest rates and income on debt are low, and the patient lending sector is willing to decumulate its debt holdings in order to maintain consumption. 
This is the solution to a relatively standard stochastic optimal control problem. We are able to obtain (and numerically solve) an ordinary differential equation for the consumption of the impatient borrowing sector as a function of the single state variable (leverage) and the Fokker-Planck equa-

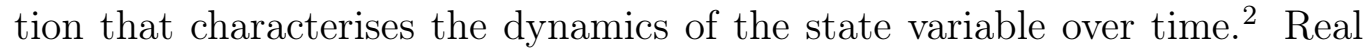
interest rates and consumption of the patient lending sector then emerge from market clearing conditions. We are able to show that there is only one solution to these equations consistent with the requirement that the leverage constraint is never reached (if it was to be reached then the impatient household would be subject to an infinite local volatility of consumption, something ruled out by the assumption of a standard expected discounted utility function).

While our contribution is solidly in the modern tradition of representative agent modelling with forward looking expectations, we revive themes from much older literatures. We are able to discuss the consequences of the distribution and composition of wealth for the dynamics of consumption and interest rates highlighted, for example, by both the Austrian School von Böhm-Bawerk [1959],Von Mises [1963|) and by Metzler [1951]. We show, in particular, that a sectoral shock to income and accompanying increase in leverage can be absorbed without substantial declines in consumption through a temporary decline in the real rate of interest. This market mechanism effectively protects households against such shocks even when financial markets are incomplete so these shocks cannot be directly insured. Such adjustment may however be prevented if, as suggested in the overlapping generations model of 'secular stagnation' proposed by Eggertsson and Mehrotra

\footnotetext{
${ }^{2}$ The Mathematica notebook used for numerical computation of this solution and the creation of our Figures 1-9, together with a freestanding .cdf with no requirement for a Mathematica license that can be used to explore the impact of changing model parameters, are downloadable from www.leveragecycles.lboro.ac.uk
} 
[2014], the zero lower bound on nominal interest rates prevents the required adjustment of real interest rates.

The paper is organised as follows. Section 2 locates our work in relation to previous literature. Section 3 sets out our model, distinguishing the baseline deterministic special case and outlining our solution method. Section 4 presents numerical calculations of our solution and investigates the resulting dynamics of interest rates and consumption. Section 5 summarises and concludes. An Appendix provides technical details of our solution.

\section{Related literature}

Our analysis relates to four distinct strands of the literature. One is recent work on equilibrium models of international investment and saving imbalances (and associated growth of debt) and of the level of global real interest rates. Caballero et al. 2008] assume a fall in the level of 'pledgability' of productive assets in one country ( $\mathrm{R}$ interpreted as emerging market countries) relative to that of productive assets in the other country (U interpreted as advanced countries such as the US). A reduction in pledgability in (R) (which they suggest was triggered by the Asian crisis) leads to a fall in global real interest rates and the emergence of a current account surplus in $\mathrm{R}$ and permanent current account deficit in $\mathrm{U}$ (as savers in $\mathrm{R}$ acquire assets from $\mathrm{U}$ ).

Caballero and Krishnamurthy 2009 offer an alternative explanation in which demand for safe assets reduces global real interest rates. They assume stochastic shocks to asset values that cannot be diversified away by lending and borrowing between countries (a slightly different incomplete markets assumption than we make because we focus on income shocks). With the further assumption of an exogenous stochastic inflow of investment funds 
and exogenous deterministic withdrawal of external investment they show how an increase in demand for safe assets from overseas investors pushes down domestic interest rates, reduces the premia on risky assets held by US investors, and leads to greater leverage by the intermediaries that issue US financial securities.

Our work is complementary, focussing on the dynamic response of debt and real interest rates to shocks in the presence of leverage constraints rather than on trends in the level of debt and real interest rate. The observed combination of trend increases in debt and trend decline of real interest rates can emerge in our setting (this does not require market incompleteness or indeed income uncertainty), when the initial leverage of our impatient households is initially much lower than the desired target level. We do not however claim that our assumed differences in preferences is an entirely adequate explanation of global imbalances, these require fuller explanation possibly with reference to institutional, cultural and political as well as economic mechanisms.

A second recent strand of literature, like us, investigates the dynamic response of the macroeconomy and financial markets to shocks assuming agent heterogeneity and incomplete financial markets ${ }^{3}$ Amongst several contributions He and Krishnamurthy [2013] model risk premia on financial assets assuming a representative financial intermediary and representative final investor. They demonstrate how an equity constraint on the financial intermediary can result in jumps in required returns on risky assets following a

\footnotetext{
${ }^{3}$ There is also a longstanding literature exploring the macroeconomic and general equilibrium implications of market incompleteness (see amongst others Magill and Shafer [1991], Magill and Quinzii [1994, 1996]). Much of this literature explores relatively general abstract specifications and investigates variety of other issues, including the existence and uniqueness of equilibrium, Pareto optimality and efficiency and potential departures from fundamentals ('bubbles') in the prices of financial assets and explanations of the equity premium puzzle.
} 
negative shock to asset values. Another line of work has explored how changes in monetary conditions and collateral valuations can create a 'leverage cycle' (see for example Geanakoplos 2009 and Geanakoplos 2010]). Adrian and Boyarchenko 2013 show how a 'value at risk' constraint can amplify shocks through financial intermediaries leverage adjustments. Brunnermeier and Sannikov [2014] who model the decisions of equity constrained 'experts', who have a comparative advantage in managing productive assets and who trade both financial and productive assets with unconstrained households. They demonstrate how falls in expert net worth result in sales of the productive asset to households. This mechanism can lead to crisis episodes, with persistent declines in both output and investment. Isohätälä et al. 2014 obtain similar persistency in a model with shocks to cash flows rather than asset productivity. Cash flow shocks that substantially increase leverage lead relatively productive firms to rent out their capital stock to relatively less productive households. If uncertainty of cash flows or the costs of recapitalisation are sufficiently large then the resulting response to shocks can again be very persistent. A mechanism very similar to our own appears in the Eggertsson and Mehrotra 2014 overlapping generations model in which there are three household sectors, the young who seek to borrow in anticipation of income when they are older, and the middle-aged and the old who recieve income and pay back debt. A 'leverage shock' in the form of a exogenous reduction in the borrowing limit on the young leads to a reduction in the demand for loans and requires a reduction in the real interest rate to restore goods market equilibrium (they go on to analyse how this can in turn lead to persistent goods and labour market disequilibrium because of the zero lower bound on nominal interest rates and wage rigidities.

Our predictions about dynamic behaviour are rather different from much 
of this recent literature. Rather than persistency, we find instead that the dynamic response of real interest rates and leverage to income shocks exhibits a relatively rapid return to steady state. The decline of real interest rates driven by precautionary saving allows reduction of the leverage of impatient households towards desired target levels. This market response to shocks turns out to be quite effective in compensating for market incompleteness i.e. the absence of any direct mechanism for insuring against macroeconomic disturbance.

Our particular modelling assumptions are drawn from another strand of literature, examining aggregate saving and consumption in the presence of non-diversifiable income risk and agent heterogeneity. This is an extensive literature motivated by the observation that the widely employed assumption in much macroeconomic modelling of agent homogeneity and complete markets is clearly rejected at the micro level, both in empirical studies of household consumption decisions and asset pricing. In an economy with complete state contingent securities households would be able insure themselves against idiosyncratic risk and consumption growth would then (given separability of consumption from leisure and other possible determinants of marginal utility) be equalized across households. Deaton and Paxson [1994] (and many others) show that this prediction is strongly rejected by microeconomic data..$^{4}$ Asset pricing behaviour has also proved difficult to reconcile with complete market representative agent models (for example the well known equity premium puzzle of Mehra and Prescott 1985 and other anomalies, see Heaton

${ }^{4}$ These observations have resulted in an extensive theoretical and empirical literature examining the implications of incomplete income insurance and and borrowing constraints for the savings and consumption decisions of individual households. The resulting precautionary savings can result in sometimes substantial departures from complete market or certainty equivalent formulations of the household consumption/ saving decision (for discussion see Browning and Lusardi $[1996 \|)$. Reviews of this literature are provided by Carroll ||2001 and Meghir and Pistaferri||2011|. 
and Lucas 1995 for discussion)

Previous contributions that, like us, examine the aggregate implications of precautionary saving include Huggett 1993, Aiyagari 1994 and Clarida [1990]. A major issue in this branch of the literature is that, while the underlying model of individual household behaviour with precautionary savings is well founded, aggregation poses a substantial challenge. This is because of the need for optimal decision making to track and take account of the entire distribution of wealth across households 5 Most of this literature takes a different approach to aggregation than we do, allowing for a continuum of heterogenous agents (whereas we have only two, patient and impatient) and analysing the resulting steady state distribution of debt across agents and resulting (non-stochastic) level of real interest rates (whereas we explore the dynamics of debt and real interest rates). A further difference is that Huggett [1993 and Aiyagari [1994 assume that all heterogeneity is entirely ex-post (arising because of a different history of idiosyncratic income shocks). In this setting they are able to demonstrate both a reduction in the equilibrium real rate of interest (as in our modelling this is a consequence of precautionary saving) and also (in Aiyagari [1994]) a reduction in the stock of productive capital. ${ }^{6}$

Our model is closest to the Clarida [1990] investigation of the steady state cross-country distribution of international debt and current account deficits, wherein this ex-post heterogeneity is combined with an additional ex-ante

\footnotetext{
${ }^{5}$ See Guvenen 2011 for a review and discussion of the different approaches taken to this aggregation.

${ }^{6}$ We could amend our model in this direction, by assuming equality in the rates of time preference in our two sectors (i.e. in our notation $r h o=r \bar{h} o$ ). In this case, if borrowing constraints are large relative to income shocks, then the predictions of our model are qualitatively changed, with households targeting leverage well away from the constrained levels and income shocks are very rarely large enough to have any large impact on real interest rates. If on the other hand borrowing constraints are very tight relative to income shocks then the predicted impact of shocks on real interest rates reemerges.
} 
heterogeneity in rates of time discount.7

Finally we can relate our work to older classic but less formal literature, in which the distribution or composition of wealth affect savings and real interest rates. A separate article could be written tracing these ideas through the history of economic thought. Our examination of this literature has turned up two major contributions, echoed in some respects by our modelling.

First, the discussion in the Austrian tradition of the impact of the distribution of wealth on the real (or in their terminology the 'natural') rate of interest rates, especially by von Böhm-Bawerk 1959. The principal assumption here (see Von Mises 1963 chapter 19 for a summary) is that relatively wealthy households are more patient than relatively poor households, and will therefore save more of their current income. A shift in the distribution of wealth from less wealthy to more wealthy households will therefore result in increased savings and a lower natural rate of interest. This is similar to the predictions of our model, in which patient households are wealthier and where negative income shocks for impatient households, increasing their leverage and reducing their wealth, increases the relative wealth of patient households and reduces real interest rates. In our simulations though the mechanism operates slightly differently, with differences in rates of time preference generating the greater wealth of the patient sector, not greater wealth generating a higher rate of time preference. Still, it is clear that we can reconcile the two analyses, interpreting the Austrian mechanism as an increase in our model of the expected output of the patient sector (in our terminology an increase of $\bar{a}$ ) resulting in both a steady state decline of real

\footnotetext{
${ }^{7}$ While relatively uncommon, similar differences in rates of time preferences are assumed in other contexts, for example recent work on long term discount rates by Jouini et al. [2010]. This assumption is also explored in textbook discussions of international extensions of the Ramsey model of capital accumulation and real interest rates (see for example Barro and Sala-i Martin 1995)
} 
interest rates and also a transitional period during which leverage adjusts towards the new steady levels (the reduction in $r-\rho$ reducing the target leverage of the impatient borrowing sector) and real interest rates are reduced by more than the steady state decline. Our results are also consonant with the Austrian tradition in that we find that a market mechanism (falling real interest rates) substantially corrects for the incompleteness of markets i.e. the absence of any insurance of idiosyncratic sectoral income risk.

Second, the widely cited paper of Metzler 1951 combining the ScitovskyPigou-Haberler real balance effect with Keynesian liquidity preference in an analysis of joint equilibrium in the markets for goods and for financial assets (i.e. securities and money). A goods market equilibrium schedule (the WW line in his Figure 1) traces different combinations of real wealth and real interest rates at which savings equals investment. Real wealth is the sum of securities (whose value is inversely related to the real interest rate) and real money (determined jointly by the nominal money stock i.e. monetary policy and the price level). Equilibrium in securities markets (his Figure 2) then requires adjustment of the real money stock to the level at which the real interest rate is consistent with both Keynesian liquidity preference (lower demand for real money requiring higher interest rates) and the equality of savings and investment (goods market equilibrium). Metzler also analyses in his Figure 3 and Appendix the dynamics of adjustment (assuming partial adjustment of both real interest rates and real money) and discusses in his Figures 4 and 5 how expansionary monetary policy i.e. open market purchases of securities by the central bank can alter the composition of wealth (reducing the ratio of securities to money) and hence permanently lower the real rate of interest. This analysis (of obvious relevance to current policies of quantitative easing which operate principally by changing the composition 
of private sector wealth) is only indirectly related to our own (our model has no role for monetary policy but instead offers a more fully stated mechanism of dynamic adjustment). The most obvious parallel is that in both our model and that of Metzler if real wealth is above long term equilibrium (our target leverage) then to maintain goods market equilibrium the level of real interest rates must fall below its expected long term level. But in his fundamentally Keynesian setting (unlike our own) the goods market can be out of equilibrium during the subsequent period of dynamic transition.

\section{The model}

\subsection{Assumptions}

There are two sectors (these could be income groups within a country, different countries, or regions within a country) each consisting of a large number of identical households. Within each sector every household receives the same income, has the same preferences and so makes the same consumption decisions. This therefore allows us to work with a representative household for each sector. Households maximise the expected discounted utility of their future consumption stream $c$. Normalising the 'mass' of households in each sector to unity, and using a bar over variables and parameters to distinguish the more patient sector from the less patient, the objective function for representative households in each sector is then to maximise respectively:

$$
\begin{aligned}
& \int_{\tau=t}^{\infty} \mathrm{e}^{-\rho(\tau-t)} u(c) \mathrm{d} \tau \quad \text { and } \\
& \int_{\tau=t}^{\infty} \mathrm{e}^{-\bar{\rho}(\tau-t)} \bar{u}(\bar{c}) \mathrm{d} \tau
\end{aligned}
$$

where $\bar{\rho}<\rho$. 
The instantaneous output (endowment) of each household in the two sectors is given respectively by:

$$
\begin{aligned}
& a \mathrm{~d} t+s \mathrm{~d} z \quad \text { and } \\
& \bar{a} \mathrm{~d} t-s \mathrm{~d} z
\end{aligned}
$$

i.e. expected output per unit time is fixed at $a$ and the only uncertainty is an idiosyncratic diffusion process $(s \mathrm{~d} z)$ fully diversified at the global level. The goods market always clears, so:

$$
c+\bar{c}=a+\bar{a}
$$

Households can borrow in order to smooth output shocks or to bring forward consumption. Accumulated (net) borrowing gives rise to the sole asset in the economy, debt claims $w$ denominated in units of the single good, which we assume are claims of the impatient sector on the patient sector (the claims of the patient sector on the impatient sector are then given by $\bar{w}=-w)$. The interest rate on these claims is given by $r$. The level of consumption is determined given the current wealth level $w$. The change in these claims therefore satisfies the stochastic differential equation:

$$
\mathrm{d} w=(a+r w-c) \mathrm{d} t+s \mathrm{~d} z=(-\bar{a}+r w+\bar{c}) \mathrm{d} t-s \mathrm{~d} z
$$

Completing the model specification, we assume that there are limits on borrowing

$$
w^{*}<w<\bar{w}^{*}
$$

with $-w^{*}>0$ representing the maximum borrowing of the impatient sector and $\bar{w}^{*}>0$ the maximum borrowing of the patient sector. 
The model is parsimonious with only two standard instantaneous utility functions $(u(c), \bar{u}(\bar{c}))$ and seven other parameters $\left(a, \bar{a}, \rho, \bar{\rho}, w^{*}, \bar{w}^{*}\right.$, and $s)$.

\section{$3.2 \quad$ Solving the model}

Here we provide an overview of the solution of the model, emphasising the supporting economic intuition and comparing the stochastic specification $s>$ 0 with the deterministic baseline $s=0$. Technical details regarding the solution are described in the Appendix. With $s=0$ we have a standard deterministic model to which the maximum principle would normally be applied yielding a semi-closed form solution. With $s>0$ the model can be solved using dynamic programming; the solution however is no longer closed form, rather it is characterised by a second-order ordinary differential equation for $c(w)$ which must be solved numerically.

Given that there are a large number of households each takes $r$ as given in their optimisation. In the $s \rightarrow 0$ limit of our stochastic model we then have a textbook deterministic model, in which consumption in the impatient sector is described by a standard Euler equation:

$$
\dot{c}=(r-\rho)\left[-\frac{u^{\prime \prime}(c)}{u^{\prime}(c)}\right]^{-1}
$$

$\rho>r>\bar{\rho}$ and so consumption of impatient households declines continuously over time at a rate that depends on the interest rate $r$ and the intertemporal elasticity of consumption $\left(-u^{\prime \prime}(c) / u^{\prime}(c)\right)^{-1}$ while consumption of patient households increases.

Introducing non-zero noise, the corresponding equation describing the time-evolution of consumption of patient households is the stochastic differ- 
ential equation or SDE:

$$
\mathrm{d} c=\{(r-\rho)\left[-\frac{u^{\prime \prime}(c)}{u^{\prime}(c)}\right]^{-1}+\underbrace{\frac{1}{2} s^{2}\left[-\frac{u^{\prime \prime \prime}(c)}{u^{\prime \prime}(c)}\right] c^{\prime}(w)^{2}}_{\text {precautionary saving term }}\} \mathrm{d} t+\underbrace{s c^{\prime}(w) \mathrm{d} z}_{\text {from income uncertainty }}
$$

In the stochastic case $s>0$ there are two additional terms which do not appear in the deterministic Euler equation. The additional term in $\mathrm{d} t$, for any given level of interest rates $r$ and consumption $c(w)$, is additional precautionary saving that reduces the rate of decline in consumption of the impatient household compared to the deterministic case. The second additional term is the diffusion in $\mathrm{d} z$ representing the impact of income uncertainty on the level of consumption.

The dependency of consumption $c(w)$ on the state variable (the level of wealth $w$ ) is then described by the following second-order ordinary differential equation: 8

$$
(\rho-r) u^{\prime}(c)=(a+r w-c) u^{\prime \prime}(c) c^{\prime}+\frac{1}{2} s^{2}\left[u^{\prime \prime \prime}(c)\left(c^{\prime}\right)^{2}+u^{\prime \prime}(c) c^{\prime \prime}\right]
$$

The global interest rate $r$ is the only market price and this adjusts to ensure goods market clearing given by (3). This requires (as shown in the Appendix) that:

$$
r(w)=\frac{\left[-\frac{u^{\prime \prime}(c)}{u^{\prime}(c)}\right]^{-1} \rho+\left[-\frac{\bar{u}^{\prime \prime}(\bar{c})}{\bar{u}^{\prime}(\bar{c})}\right]^{-1} \bar{\rho}}{\left[-\frac{u^{\prime \prime}(c)}{u^{\prime}(c)}\right]^{-1}+\left[-\frac{\bar{u}^{\prime \prime}(\bar{c})}{\bar{u}^{\prime}(\bar{c})}\right]^{-1}}-\frac{1}{2} s^{2} c^{\prime 2} \frac{\left[-\frac{u^{\prime \prime \prime}(c)}{u^{\prime \prime}(c)}\right]+\left[-\frac{\bar{u}^{\prime \prime \prime}(\bar{c})}{\bar{u}^{\prime \prime}(\bar{c})}\right]}{\left[-\frac{u^{\prime \prime}(c)}{u^{\prime}(c)}\right]^{-1}+\left[-\frac{\bar{u}^{\prime \prime}(\bar{c})}{\bar{u}^{\prime}(\bar{c})}\right]^{-1}}
$$

In the deterministic case $(s=0)$ the global interest rate is simply a weighted average of the time preferences of the two households (so $\rho>r>\bar{\rho}$ ). In

\footnotetext{
${ }^{8}$ This equation is a transformation of the equation of optimality, or Hamilton-JacobiBellman equation, which characterises the consumption policy that maximises the expected discounted utility objective equation (1a). See Appendix for details.
} 
the stochastic case $(s>0)$ there is an additional term, the second expression on the rhs of eq. (9) generated by the desire for precautionary saving. This lowers the real rate of interest downwards to restore goods market clearing. Equations (8), (9) and (3) together yield a somewhat complicated looking (but fairly easily numerically solved) ordinary differential equation for $c(w)$. This ODE is second-order and two boundary conditions are required for solution. We establish the existence of unique solution by considering the behaviour of the steady state or 'ergodic' probability density function $f(w)$ of $w$. In these sort of stochastic models the ergodic density is usually identified with the steady state cross sectional density of the state variables for a large population of (independent) households all governed by the same dynamic stochastic equations of motion. However for our model this is not an appropriate interpretation because we assume all households are hit by the same shocks, so at any point in time all households in a given sector have the same wealth. Instead this ergodic distribution should be thought of as the time-independent or unconditional distribution of $w$ obtained by sampling the economy at a random points of time.

This ergodic distribution can be obtained from the Kolmogorov forward equation, also known as the Fokker-Planck equation, giving the time-dependent probability density function conditional on initial state of $w$. In the stationary limit, it reduces to the following first order ordinary differential equation 9 for the ergodic density $f(w)$ :

$$
0=[a+r(w) w-c(w)] f(w)-\frac{1}{2} s^{2} f^{\prime}(w)
$$

where $f$ is subject to the normalisation condition, $\int_{w^{*}}^{\bar{w}^{*}} f(w) \mathrm{d} w=1$. Our

\footnotetext{
${ }^{9}$ In general, the left-hand side is a non-zero constant, however, when there are no sink or source states, that constant is zero.
} 
Appendix discusses the corresponding time dependent equation $f(w, t)$ which is what we actually solve for in our numerical coding.

To obtain boundary conditions for $c$, eq. (8), we require that the households never attain the boundaries $w^{*}, \bar{w}^{*}$ which means that

$$
f\left(w^{*}\right)=f\left(\bar{w}^{*}\right)=0 .
$$

These conditions ensure that while households may approach the boundaries for maximum borrowing, they never actually reach these states ${ }^{10}$. If instead the boundaries were attainable, then once on the boundary the household could no longer smooth consumption, and the infinite local variance in income creates an unlimited penalty in terms of the objective eq. (1a) i.e. the optimisation is no longer well defined.

Normalisation and eq. (11) would appear to give three conditions for a first order ODE, eq. (10). However, in the Appendix, we show that the zero density boundary condition is equivalent to

$$
c^{\prime}\left(w^{*}\right)=c^{\prime}\left(\bar{w}^{*}\right)=+\infty
$$

so that the boundary condition for the ergodic density in fact implies the boundary conditions for $c$. The above eq. 12 together with the normalisation for $f$ totals three conditions for the third order ODE system that eqs. (8) and 10 form, making the problem fully determined.

In addition, as we show in the Appendix, asymptotically the functions $c$,

\footnotetext{
${ }^{10} \mathrm{~A}$ boundary state could also be unreachable if the noise vanishes at that point; this is not the case here as the standard deviation $s$ is constant.
} 
$r$, and $f$ behave as

$$
\begin{aligned}
& c(w)=c_{0}+c_{1}\left(w-w^{*}\right)^{\frac{1}{2}}+o\left(\left(w-w^{*}\right)^{\frac{1}{2}}\right), \\
& r(w)=-\frac{1}{4} s^{2} \frac{1}{\left|w^{*}\right|}\left(w-w^{*}\right)^{-1}+o\left(\left(w-w^{*}\right)^{-1}\right), \\
& f(w)=f_{0}\left(w-w^{*}\right)^{\frac{1}{2}}+o\left(\left(w-w^{*}\right)^{\frac{1}{2}}\right),
\end{aligned}
$$

where $c_{0}$ is consumption at $w^{*}$, and $c_{1}$ and $f_{0}$ are constants chosen so that the above $c$ satisfies eq. (8) to leading order, and that $f$ is normalised to unity, while the value of $c_{0}$ is chosen so that eq. (12) is satisfied. Note from eq. (13b) the interest rate must tend to minus infinity as $w \rightarrow w^{*}$. Analogous formulae and results hold at the upper boundary.

\section{$4 \quad$ Numerical solution}

We have calculated numerical solutions of the stochastic version of the model in the case of iso-elastic instantaneous utility 11

The parameter assumptions are as follows (using a bar to indicate parameters of the households in the patient sector):

\footnotetext{
${ }^{11} \mathrm{~A}$ numerical solution for both $c(w)$ and $f(w, t)$ subject to the boundary conditions at $w=w^{*}$ and $w=\bar{w}^{*}$ are obtained using the pseudospectral Chebyshev collocation method in conjunction with Newton iterations. Although more commonly encountered in the context of partial differential equations, the methods can be employed to solve systems of ordinary differential equations as well. For reference, see e.g. Quarteroni and Valli 2008]
} 
Parameter

Rate of time preference

Inverse intertemporal elasticity of

substitution

Expected output per annum

Standard deviation of output per

annum

Leverage constraint
Impatient sector Patient sector

$$
\begin{array}{ll}
\rho=0.05 & \bar{\rho}=0.03 \\
\varepsilon=1.5 & \bar{\varepsilon}=1.5
\end{array}
$$

$$
a=1 \quad \bar{a}=1
$$

$$
0 \leq s \leq 0.5
$$

$$
w \geq w^{*}=-5 \quad w \leq \bar{w}^{*}=+5
$$

Figures 1-9 report our numerical solutions with these assumed parameters (for some figures we use only the single value $s=0.2$ ). Figure 1 shows the rate of interest $r(w)$ as a function of $w$ for different levels of income uncertainty $s$. The inset to the figure shows a magnified section $r(w)$ near $w^{*}$. Close to the leverage constraint the real interest rate falls well below the rate of time preference of the patient sector $(\bar{\rho}=0.03)$ and when the leverage constraint is very close actually becomes negative (thus creating a positive income for the borrowing impatient sector).

Figure 2 shows the expected level of saving $(a+r w-c(w))$ as a function of $w$. It can be seen that for very low levels of wealth the precautionary motive leads to positive saving as the indebted households seek to reduce their leverage and increase $w$. For higher levels of wealth then the time preference dominates and there is dissaving.

Figure 3 shows the level of consumption $c(w)$ as a function of $w$. Consumption, as expected, increases with wealth. Close to the leverage constraint for the impatient sector, consumption of the patient sector rises 


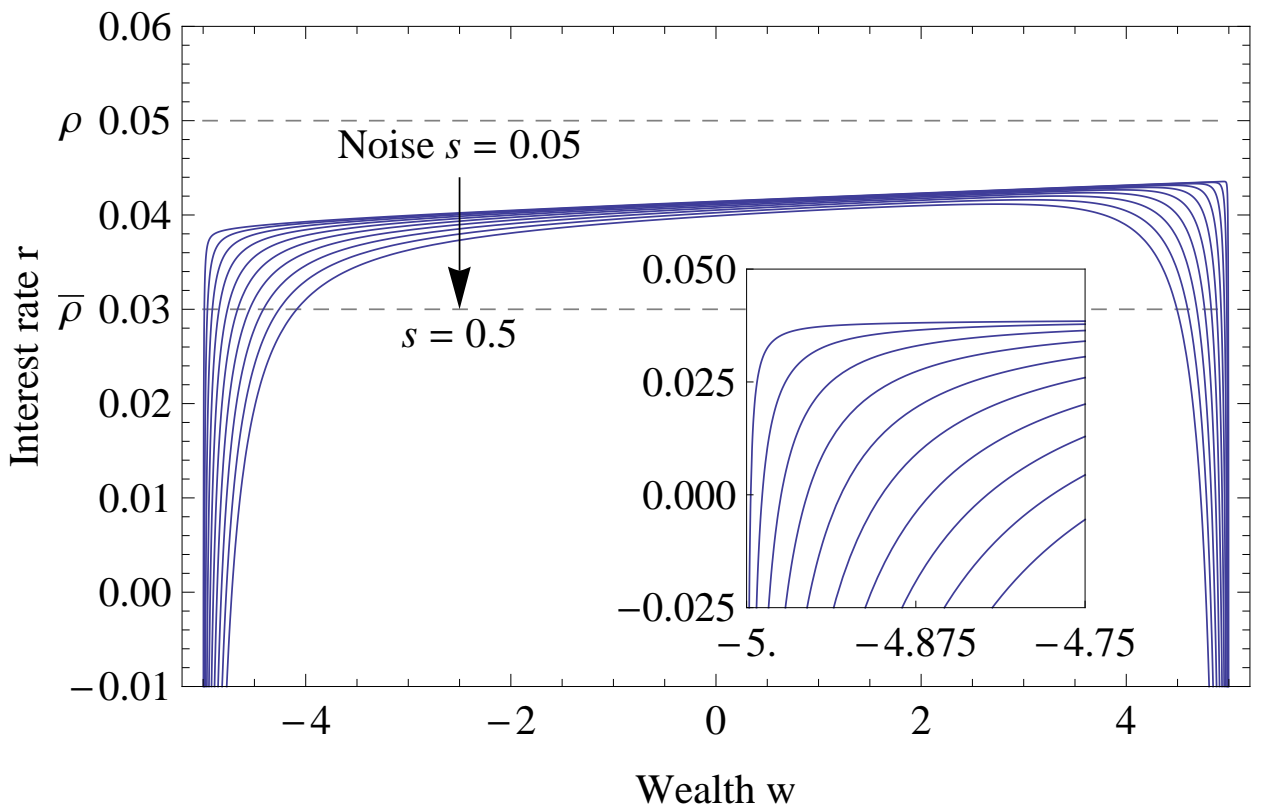

Figure 1: Interest rate $r$ as function of wealth $w$.

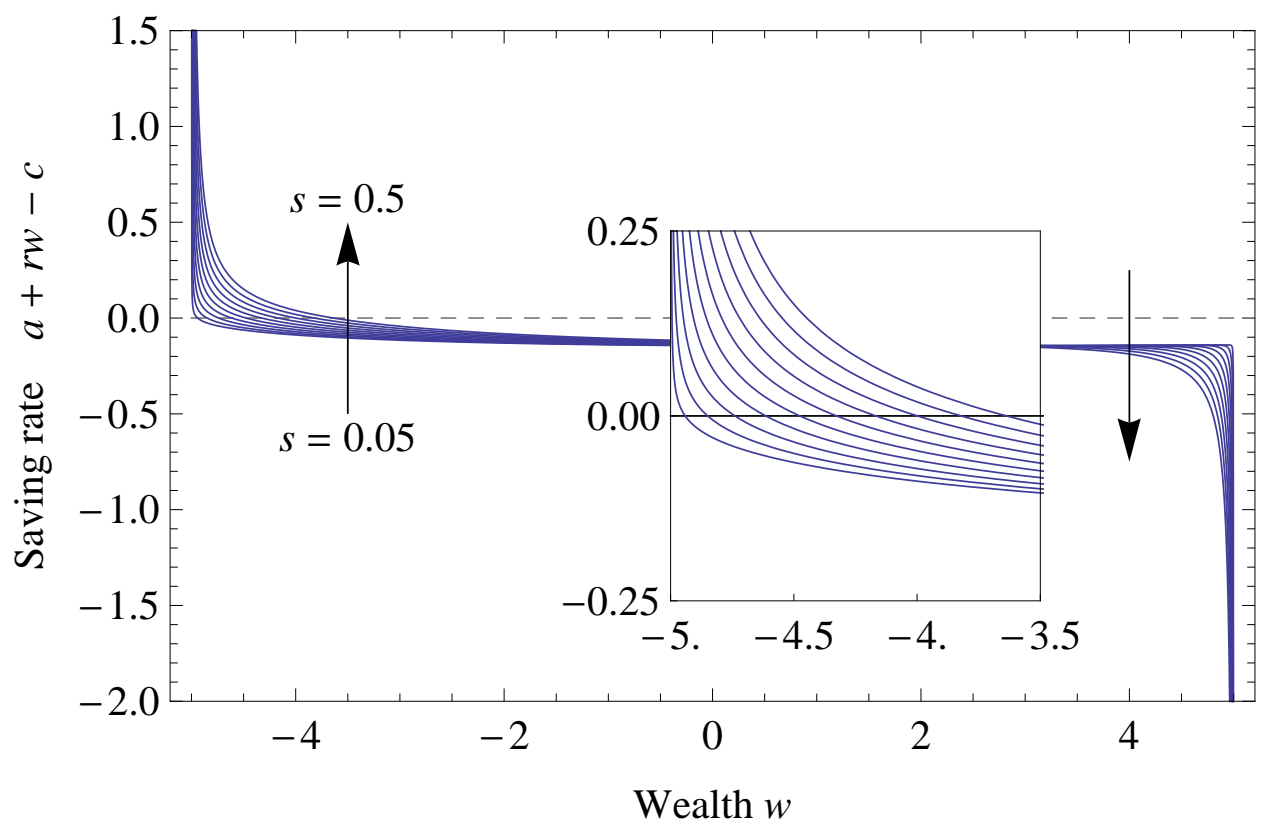

Figure 2: Expected saving $a+r w-c$ as a function of wealth $w$. 


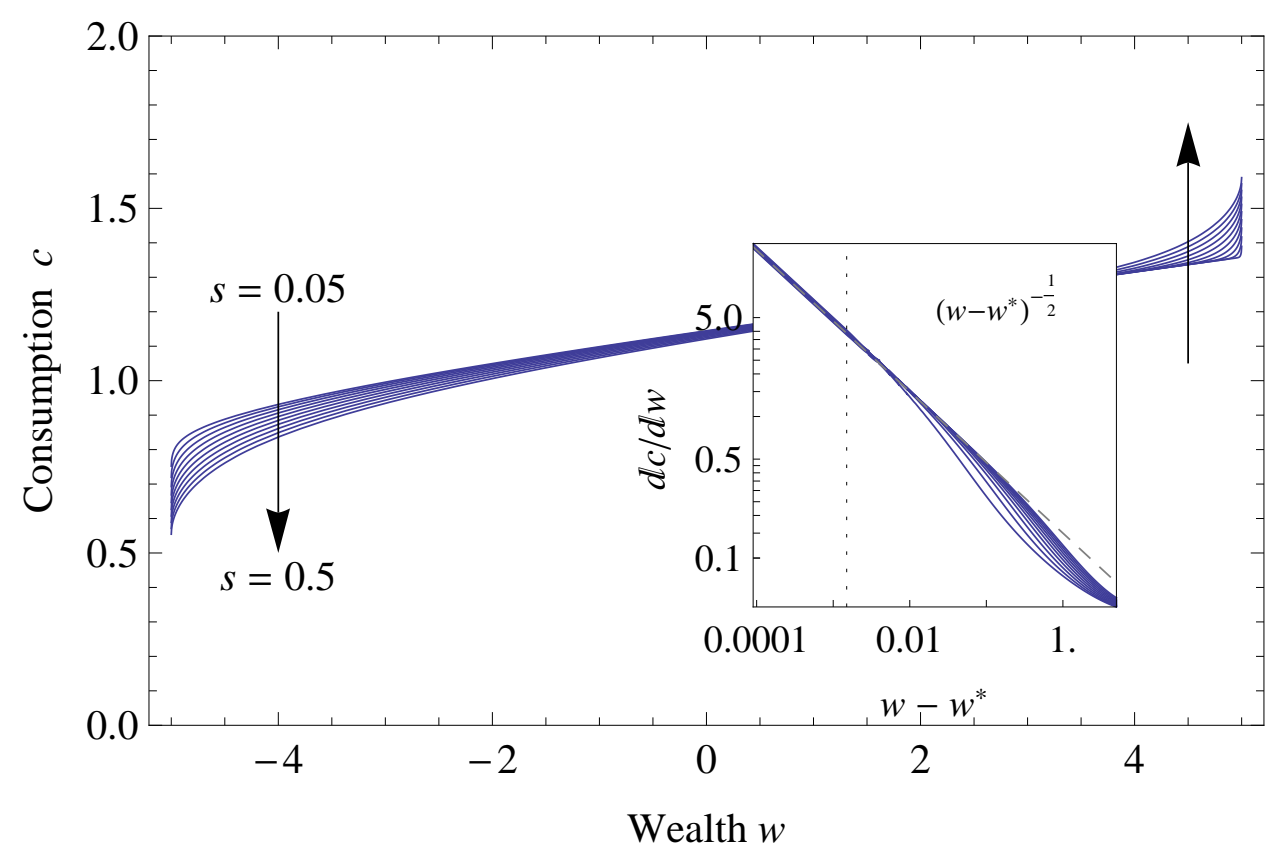

Figure 3: Consumption $c$ as a function of wealth $w$. Inset: $c^{\prime}$ on logarithmic scale comparing to power law $\left(w-w^{*}\right)^{-1 / 2}$.

sharply and consumption of the impatient sector fall sharply, due to the joint impact of lower interest rate and the prudential saving of the impatient sector seeking to keep away from the leverage constraint. The decline of consumption is however relatively modest, compared to the fall of the interest rate shown in Figure 1$]^{12}$

Figure 4 shows the ergodic density for different values of the standard deviation of income $s$. For low levels of $s, 5 \%$ of annual income $a$, the ergodic density is concentrated near the maximum level of borrowing, the figure suggests that the density lies almost entirely between $w=-4$ and $w=w^{*}=-5$. As $s$ increases the density both shifts to the right and widens. For higher values of $s$, the figure runs up to $50 \%$ of annual income $a$, but

\footnotetext{
${ }^{12} \mathrm{~A}$ technical issue explored in the inset to the figure, is the accuracy of the asymptotic expansion for $c(w)$ Eq. 13a applied when $w$ is close to $w^{*}$. The logarithm of $c$ is as predicted linear in $\left(w-w^{*}\right)$ with a slope of $-1 / 2$ and this approximation is accurate well beyond the range at which the asymptotic expansion is used for numerical calculation.
} 


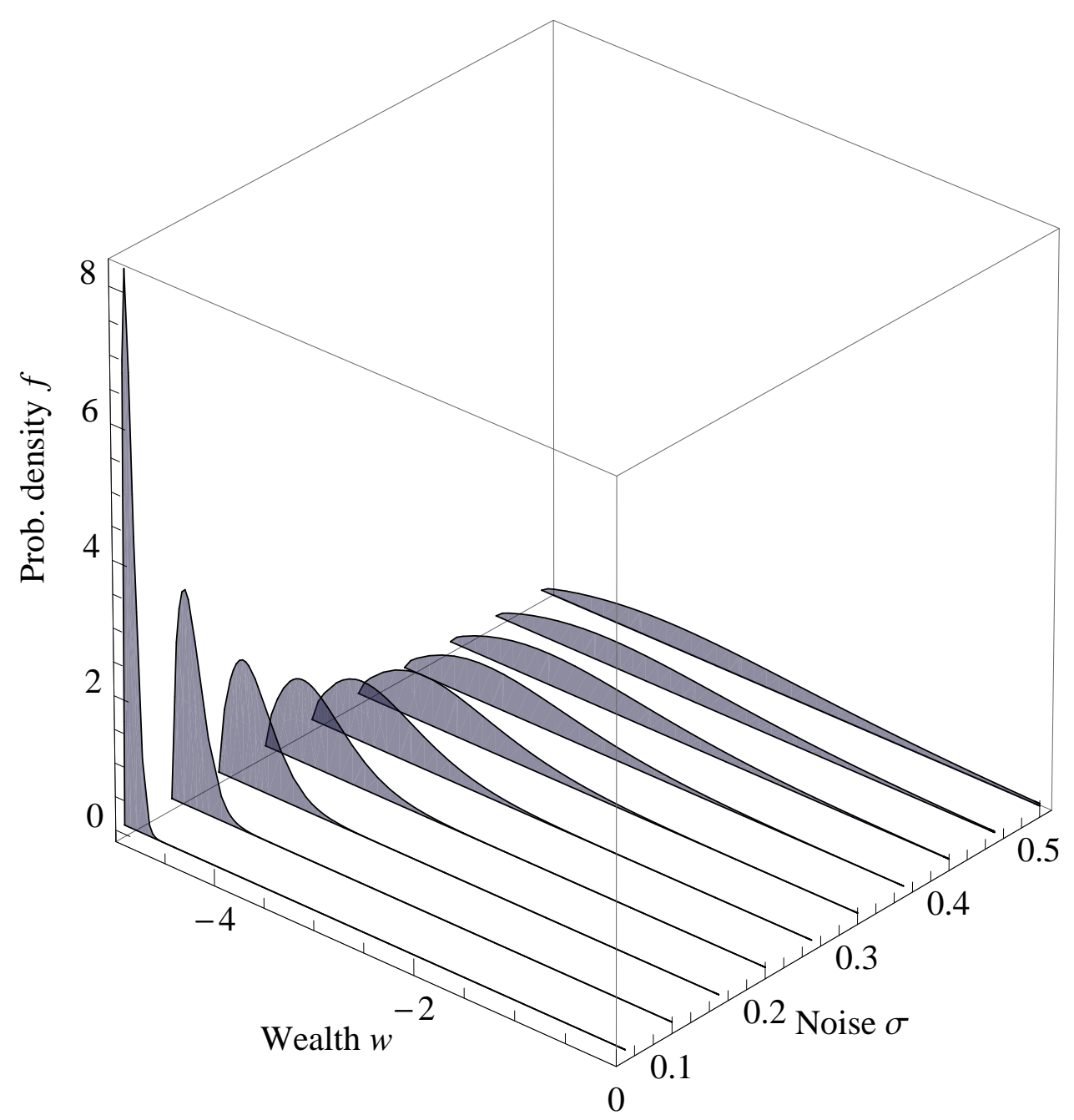

Figure 4: Probability density $f$ as a function of wealth $w$ and noise $s$.

even with this highly uncertain level of income is concentrated in the range $w=0$ to $w=w^{*}=-5$.

Figure 5 and Figure 6 show versions of Figures 4 and then Figure 1 , using a rescaled measure of wealth with zero mean and a standard deviation of unity. The purpose of these figures is to demonstrate a key feature of our model, that households target a buffer of leverage $(w-w *)$ relative to the leverage constraint $(w *)$ and this buffer is approximately linear in the standard deviation of income shocks. As a consequence, once this buffer stock 


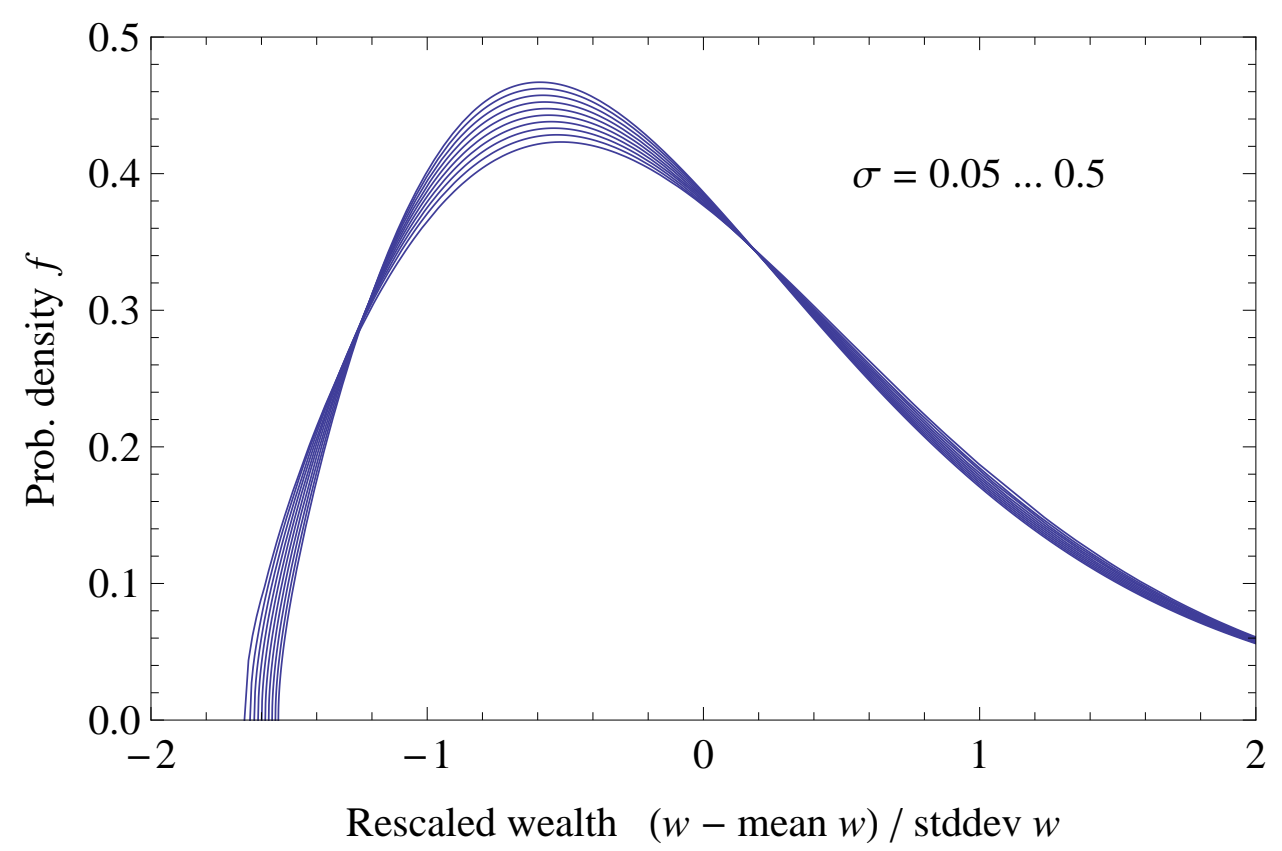

Figure 5: Wealth probability density as a function of normalized wealth.

behaviour is taken into account the predictions of our model about wealth and interest rate dynamics turn out to be relatively insensitive to income uncertainty: 13

Figure 5 shows the rescaled ergodic density function $f(w)$ (the pdf relative to the mean) is relatively little affected by the standard deviation of income $s$. Using this same rescaling of wealth, the interest rate function $r(w)$ (and consumption $c(w)$, though this is not shown here) vary only slightly with changes in the standard deviation of income $s$. Note also that for all values of $s$ shown here, from $5 \%$ to $50 \%$ of annual income, a sharp fall in $r$ occurs once wealth $w$ declines to about 1.2 to 1.6 standard deviations below its mean.

Figures 7 to 8 illustrate the impulse-response dynamics of wealth and

\footnotetext{
13 the simulator downloadable from our research web pages shows that these predictions are similarly insenstive to the magnitude of the leverage constraint $w^{*}$
} 


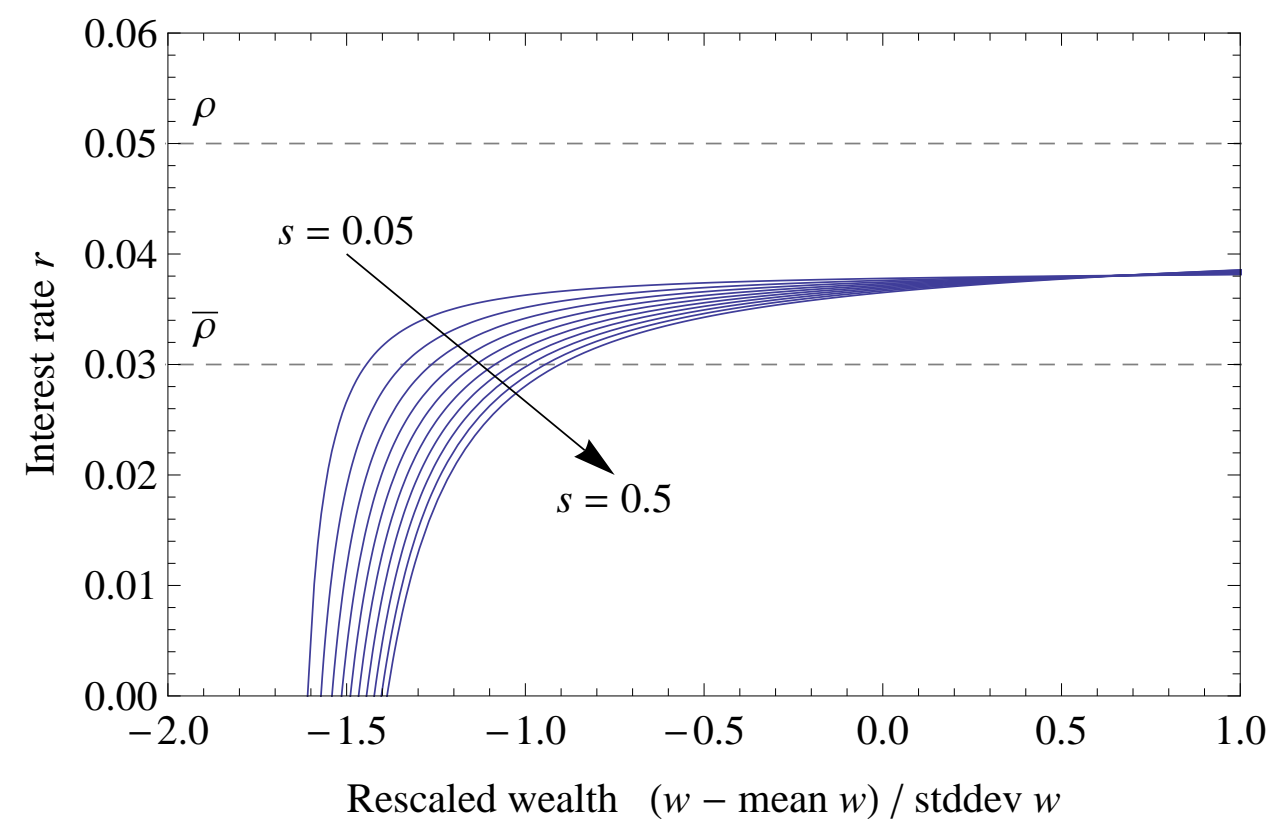

Figure 6: Interest rate as a function of normalized wealth.

interest rates following a fall in wealth to 1.5 standard deviations below its mean (these Figures assume that the standard deviation of income is $20 \%$ of annual income i.e. $s=0.2$ ). All impulse response data is computed by solving the time-dependent probability distribution $f(w, t)$ conditional on the initial $w$, described in the Appendix. Note that these impulse responses can be interpreted either as the response of wealth and real interest rates following a series of income shocks which increase leverage relative to the desired target level or as the response following a one-off increase in the leverage constraint that is not expected to change any more in the future. In both cases the buffer of leverage above the constraint is reduced and is then subsequently rebuilt, through lower real interest rates and also reduced consumption.

Because this is a stochastic model the dynamics are not a single line, rather starting from this initial point, the future evolution of wealth is a 


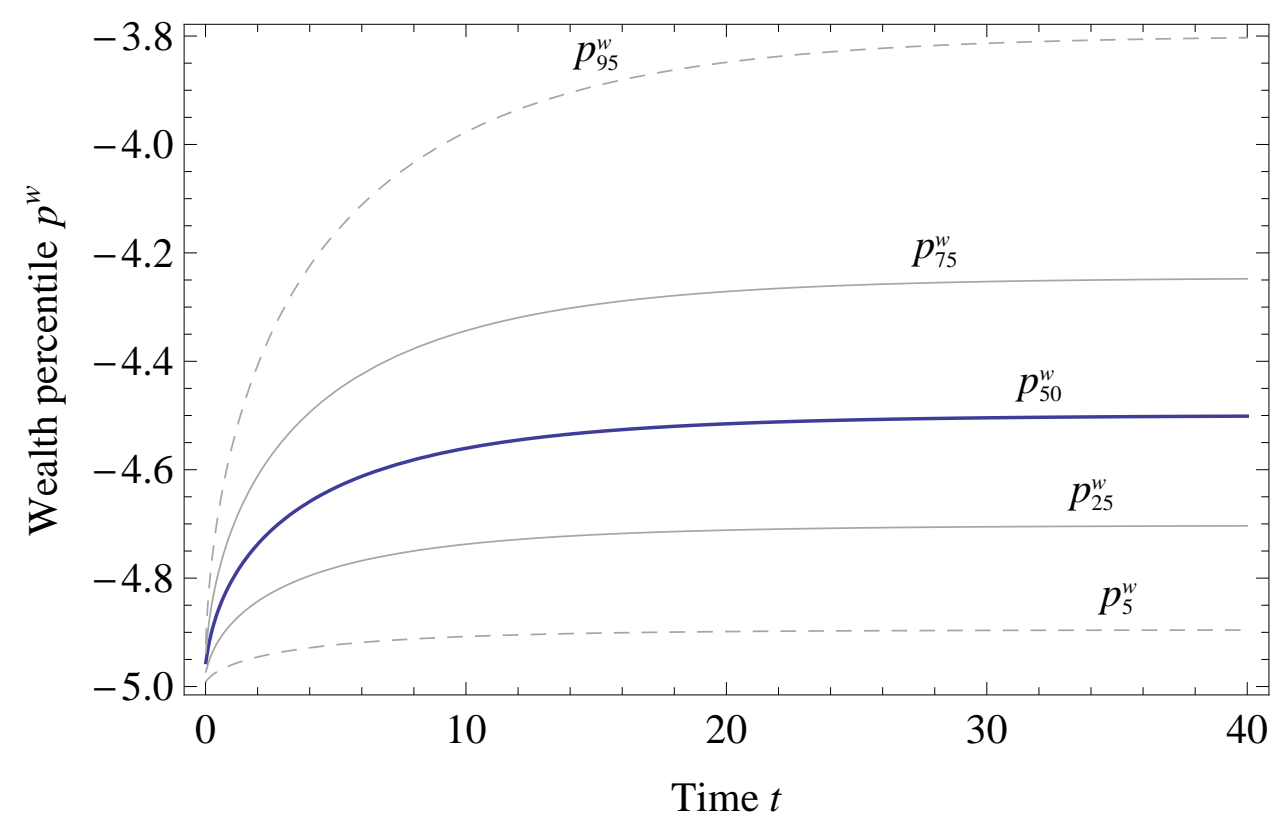

Figure 7: Selected wealth percentiles as functions of time.

density function that gradually spreads out from the initial starting point. The heavy line in Fig. 7 and 8 show the median (50th percentile) of the distribution. Below this the figure shows the 5th and 25th percentiles, above this the 75 th and 95th percentiles.

Figure 7 shows that to begin with, following a fall in wealth, with the density of $w(f(w, t))$ adjusts fairly rapidly towards the long run ergodic density $f(w)$, so by the end of the second year $(t=2)$ the median has closed to within one standard deviation of its steady state level. Overtime the rate of adjustment slows down, it takes until about the end of the fourth year $(t=4)$ before the median is within half a standard deviation of its steady state level, and by about year twenty $(t=20)$ no difference can be seen in this chart between the median and its steady state level. There is a similar pattern of adjustment for the other percentiles, fast to begin with and gradually slowing down. The adjustment of the higher percentiles is rather 


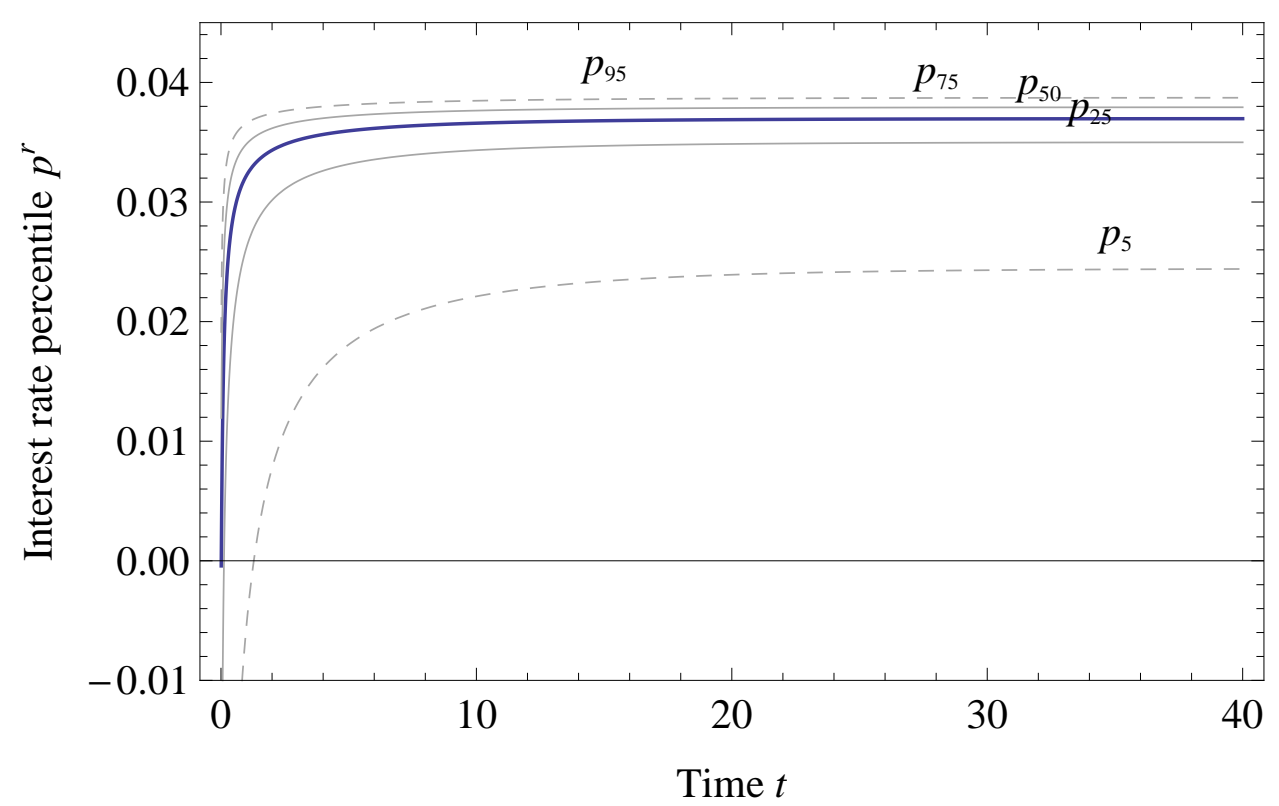

Figure 8: Selected interest rate percentiles as functions of time.

slower than the lower percentiles, taking until around year 30 before there is no further visible change in the 95th percentile of the distribution.

Figure 8 shows the corresponding impulse response for real interest rates, if wealth falls to 1.5 standard deviations below its mean. Because of the highly non-linear dependency of interest rates $r(w)$ on wealth $w$ (Figure 1), the rate of adjustment of interest rates varies substantially over time, extremely rapid during the first year (up to $t=1$ ), slowing substantially over the next three years (until $t=4$ ) and then only gradually correcting back to the long run ergodic density, and with no visible further time dependence after twenty years $(t=20)$.

Finally Figure 9 reports the cumulative density of $r$, presented with a log scale on the vertical axis to make it easy to read off the different percentiles of the steady state density. This Figure is a convenient summary of the frequency of episodes in which real interest rates fall below any particular level and how this frequency varies with the standard deviation of income 


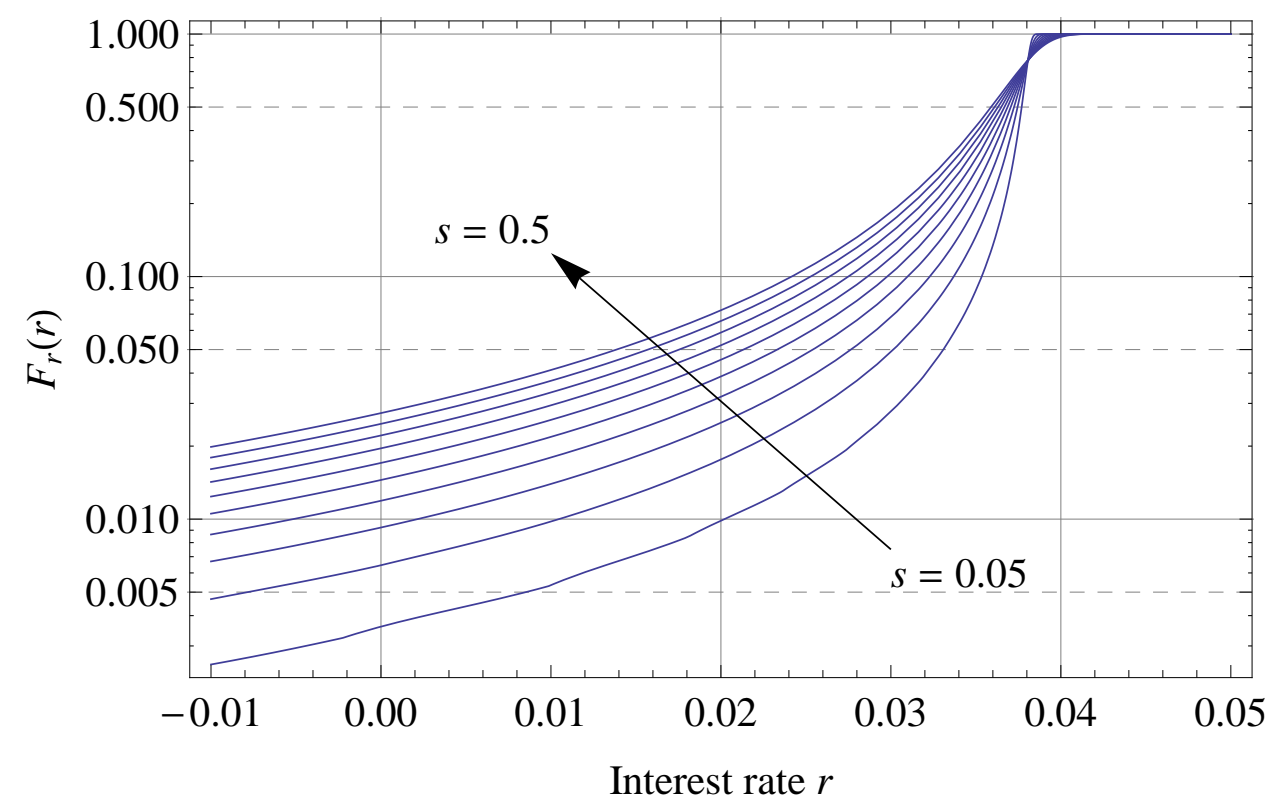

Figure 9: Interest rate cumulative density $F_{r}$.

shocks. Focussing on the vertical line at $r=0$ it can be seen that when $s=0.05$ this corresponds to a cumulative density of about $0.2 \%$, i.e. the negative real interest rates are observed only $0.2 \%$ of the time. This compares to the baseline of $s=0.2$ where negative real interest rates occur a little over $1 \%$ of the time and to the upper value of $s=0.5$ when negative real interest rates occur around $3 \%$ of the time.

This figure can also be read horizontally as well as vertically. For example the horizontal dotted line in the figure at a height of $F(r)=0.05$, shows the 5th percentile of the distribution for different value of $s$. For our baseline choice of $s=0.2$ this is at about $2.5 \%$ - i.e. about one twentieth of the time real interest rates will be below $2.5 \%$ - compared to a median value of around $3.7 \%$. As this figure shows increasing the value of $s$ has little impact on the median but has a quite substantial impact on the lower percentiles of the distribution, with 5th percentile falling to around $1.4 \%$ as $s$ rises to 
$0.5 \%$.

\section{$5 \quad$ Summary and conclusions}

Amongst the most striking trends in the global macroeconomy over the past thirty five years have been the substantial increases of both private and public sector debt and the simultaneous decline in global real interest rates (Buttiglione et al. 2014, IMF 2014). This paper examines the consequences of such increases in leverage for the dynamic response of consumption and real interest rates to shocks.

We analyse consumption and real interest rate dynamics in a stylized model of macroeconomic exchange with two household sectors (one patient, the other impatient) motivated to save income as a precaution against the risk that a series of income shocks might push their leverage towards exogenously imposed maximum limits. The outcome is precautionary saving and buffer stock wealth management by our two representative households, paralleling the well established buffer stock wealth management and precautionary saving by individual households at the microeconomic level.

In our setting financial markets are incomplete (there is no insurance against income shocks so debt must do 'double duty', allow households optimally to allocate their consumption over time and to manage income shocks). Despite this market incompleteness, market exchange allows households to avoid substantial variation in levels of consumption (Figure 3). Impatient households avoid fluctuations in consumption by targeting a buffer of unused leverage, consuming less than their expected net income if leverage (negative wealth) is above this target level (the positive expected saving to the left of our Figure 2). General equilibrium then requires that total consumption, by 
the two households, equals total income (for simplicity we make this total income constant, i.e. negative income shocks to one sector are always offset by positive income shocks to the other sector) in turn requiring sometimes substantial but short lived falls in real interest rates (Figure 1) that effectively transfer income from the patient households holding debt claims to the impatient households issuing debt claims.

This solution is obtained using standard if somewhat technical assumptions and methods. Time $t$ is continuous and income shocks are increments of a diffusion process $s \mathrm{~d} z$. This allows us to characterise solution as a simple second order ODE in a single state variable $c(w)$ representing the consumption of impatient households as a function of their wealth (leverage is negative wealth) together with an accompanying PDE, the Fokker-Planck equation for $f(w, t)$ describing the stochastic time evolution of wealth. There is a unique solution to these equations consistent with the boundary conditions (expressed via asymptotic expansions) which ensure that the leverage constraints are approached but never actually breached.

A notable feature of this solution is that the real interest rates asymptote towards $r=-\infty$ at the boundary of maximum leverage $w=w^{*}$ (the resulting subsidy to indebted households is needed in order to prevent income shocks leading to a breach of maximum leverage). The possibility of large negative interest rates is a more reasonable feature of the model than might at first be apparent. Negative interest rates arise only very occasionally (indicated by the cumulative density functions reported in our Figure 9) and, following large shocks, the long term distribution of leverage and real interest rates is restored relatively rapidly (Figures 7 and 8).

A second notable feature is that the predictions of this model are not particularly dependent on either the size of the leverage constraint $\left(w^{*}\right)$ or 
the magnitude of income uncertainty $s \mathrm{~d} z$. This is a consequence of buffer stock wealth management. Households target a buffer of leverage above the constraint (Figure 4). This means that the absolute value of the constraint itself does not much matter). The magnitude of this buffer is approximately linear in $s$. This means that the dynamics of consumption and real interest rates in response to shocks (the increments to the diffusion process $s \mathrm{~d} z$ ) are very much the same for different values of $s$ (Figures 5 and 6 ).

To what extent can our model be used for addressing current macroeconomic policy concerns? We are deliberately agnostic about the interpretation of our patient and impatient sectors. One possibility is that these represent countries, for example the well known global imbalance between high saving and low saving countries often suggested as an underlying cause of the increase of global indebtedness. We are cautious about applying our model too literally in this context. A fuller model of the dynamic response of these saving imbalances would we believe emerge from considering shocks to rates of productivity growth rather than to income shocks and making allowance for responses in real exchange rates. This could be done in a model similar to our own but would necessitate using more state variables and hence require a more complicated mathematical model and solution. In the global context the predictions of our model are also somewhat counterfactual. For example, while global real interest rates did indeed fall in the wake of the global financial crisis of 2008, this has been a continuation of the previous trend and post-crisis there has been no rapid reduction in leverage or rebound in global real interest rates.

Still our modelling points to one definite conclusion: high levels of debt need not be a major macroeconomic problem provided that financial market prices, in our model the real rate of interest, can adjust freely to reflect indi- 
vidual preferences. Wealth and consumption can then adjust dynamically to prevent uninsured income shocks leading to substantial declines in consumption. An obvious direction for future research, building on our initial effort, will be to examine how robust this finding is in other more realistic contexts. This would require extending our modelling in several different directions: for example to a world of international trade with more than one good and an endogenous real exchange rate; to allow for storage and for production and capital investment (work of this kind has been undertaken in the recent literature on leverage cycles, briefly reviewed in our Section 2); to allow for more realistic treatment of shocks for example disturbances to the anticipated growth of income or autocorrelation of shocks to capture observed business cycle fluctuations; and most importantly by introducing monetary exchange and a distinction between real and nominal interest rates. In a monetary model it is possible that constraints on financial market prices (for example as in the analysis of 'secular stagnation' provided by Eggertsson and Mehrotra 2014] the zero-lower bound on nominal interest rates) could introduce much more protracted dynamics than in our modelling, hinder a market adjustment to income or other shocks and explain why in practice lower real interest rates have not been accompanied by global deleveraging. 


\section{A Appendix: Model Solution}

This appendix contains technical details regarding the model solution that were omitted in the main text. It first discusses the solution of the stochastic model using dynamic programming. It then discusses the boundary conditions and derives the asymptotic expansions used to implement these conditions. Finally it discusses the solution of the time-dependent Fokker-Plank equation $f(w, t)$ used for analysing the dynamics of the model.

\section{A.1 Solution of the stochastic problem using dynamic programming}

The goal is to solve for consumption $c(w)$ as function of net lending/borrowing $w$ The first step is to derive the optimal consumption rule for impatient household maximises the objective function, eq. (1a) (the derivation for the patient household entirely parallels that for the impatient household, so is suppressed here). Let $V$ be the function for which the objective is maximal:

$$
V\left(w_{0}\right)=\max _{c} \mathbb{E} \int_{0}^{\infty} \mathrm{e}^{-\rho t} u[c(t)] \mathrm{d} t .
$$

We distinguish the wealth and consumption of an individual household indexed by $j\left(w_{j}, c_{j}\right)$ from the wealth and consumption of the representative agent $(w, c)$. The value function $V\left(w_{j}, w\right)$ for the individual agent satisfies the Hamilton-Jacobi-Bellman equation (the interest rate $r$ is unaffected by individual household wealth i.e. each household is a price taker in the capital 
market):

$$
\begin{array}{r}
\rho V\left(w_{j}, w\right)=\max _{c}\left[u(c)+\left(\begin{array}{ll}
a+r(w) w_{j}-c_{j}, & a+r(w) w-c
\end{array}\right)\left(\begin{array}{l}
V_{w_{j}} \\
V_{w}
\end{array}\right)\right. \\
\left.+\frac{1}{2} s^{2}\left(\begin{array}{l}
1, \\
1
\end{array}\right)\left(\begin{array}{ll}
V_{w_{j} w_{j}} & V_{w_{j} w} \\
V_{w_{j} w} & V_{w w}
\end{array}\right)\left(\begin{array}{l}
1 \\
1
\end{array}\right)\right]
\end{array}
$$

Maximising the right-hand side of eq. (15), the first order condition for the choice of $c_{j}$ is

$$
V_{w_{j}}=u^{\prime}\left(c_{j}\right)=u_{j}^{\prime}
$$

To obtain an ODE for optimal consumption $c$ we differentiate the HJB, eq. (15), with respect to $w$ and substitute for optimal consumption.

We next proceed to aggregation. In equilibrium, since all households are alike, $w_{j}=w$ and $c_{j}=c$ i.e. the $j$ subscripts can be dropped. We need though to consider small departures of consumption out of equilibrium in order to evaluate the derivatives.

With the above assumptions, the HJB equation for consumption $c$ becomes:

$$
[\rho-r(w)] \frac{u^{\prime}(c)}{u^{\prime \prime}(c)}=[a+r(w) w-c] c^{\prime}+\frac{1}{2} s^{2}\left[\frac{u^{\prime \prime \prime}(c)}{u^{\prime \prime}(c)} c^{\prime 2}+c^{\prime \prime}\right]
$$

In order to solve for $r$ we take the resource constraint $c(w)+\bar{c}(\bar{w})=$ $a+\bar{a}$, differentiate it with respect to $w$, and substitute using the $c$ differential 
equations, and the fact $w=-\bar{w}$. This yields

$$
r(w)=\frac{\left[-\frac{u^{\prime \prime}(c)}{u^{\prime}(c)}\right]^{-1} \rho+\left[-\frac{\bar{u}^{\prime \prime}(\bar{c})}{\bar{u}^{\prime}(\bar{c})}\right]^{-1} \bar{\rho}}{\left[-\frac{u^{\prime \prime}(c)}{u^{\prime}(c)}\right]^{-1}+\left[-\frac{\bar{u}^{\prime \prime}(\bar{c})}{\bar{u}^{\prime}(\bar{c})}\right]^{-1}}-\frac{1}{2} s^{2} \frac{\left[-\frac{u^{\prime \prime \prime}(c)}{u^{\prime \prime}(c)}\right]+\left[-\frac{\bar{u}^{\prime \prime \prime}(\bar{c})}{\bar{u}^{\prime \prime}(\bar{c})}\right]}{\left[-\frac{u^{\prime \prime}(c)}{u^{\prime}(c)}\right]^{-1}+\left[-\frac{\bar{u}^{\prime \prime}(\bar{c})}{\bar{u}^{\prime}(\bar{c})}\right]^{-1}} c^{\prime 2} .
$$

The first term here is the expression for $r$ that applies in the deterministic case. The second additional term in $\frac{1}{2} s^{2} c^{\prime}(w)^{2}$ is a correction that depends on the absolute prudence, $-u^{\prime \prime \prime}(c) / u^{\prime \prime}(c),-\bar{u}^{\prime \prime}(\bar{c}) / \bar{u}^{\prime \prime}(\bar{c})$, and absolute risk aversion, $-u^{\prime \prime}(c) / u^{\prime}(c),-\bar{u}^{\prime \prime}(\bar{c}) / \bar{u}^{\prime}(\bar{c})$ of the two sectors. Eq. (17) together with $r(w)$ as given by eq. (18) form an ordinary differential equation from which aggregate consumption $c$ can be solved.

\section{A.2 Boundary conditions and asymptotic expansions}

As our boundary condition, we ask that

$$
\lim _{w \rightarrow w^{*}} f(w)=0
$$

effectively requiring that household behaviour is such that it completely avoids the borrowing limit. We only consider the behaviour at the lower boundary $w^{*}$, and attempt to find the shape of $c$ and $f$ that are consistent with the above. The calculation for the upper boundary is essentially identical.

A formal solution to the Fokker-Planck equation, eq. (10) gives the ergodic density

$$
f(w)=C \exp \left\{\frac{2}{s^{2}} \int_{0}^{w}\left[a+r\left(w^{\prime}\right) w^{\prime}-c\left(w^{\prime}\right)\right] \mathrm{d} w^{\prime}\right\}
$$

where $C$ is a constant of integration. In order for $f\left(w^{*}\right)$ to be zero, the integral 
in the exponential must tend to $-\infty$ as $w$ goes to $w^{*}$. Since the interest rate is the only quantity in the integrand that is not bounded, we must have that $\lim _{w \rightarrow w^{*}} r(w)=-\infty$. A similar argument gives us the boundary condition $c^{\prime}\left(w^{*}\right)=+\infty$ : On inspection of the expression for $r(w)$, eq. (18), one sees that the only unbounded term is the one proportional to $c^{\prime}(w)$ (assuming non-zero third derivatives of the utility functions), since consumption and its utility are bounded and $-u^{\prime \prime}(c) / u^{\prime}(c)>0,-\bar{u}^{\prime \prime}(\bar{c}) / \bar{u}^{\prime}(\bar{c})>0$ by monotonicity and concavity of $u, \bar{u}$. Thus, $r\left(w^{*}\right)$ is infinite if and only if $c^{\prime}\left(w^{*}\right)=\infty$.

The next task is to find solutions (if any) to eq. (17) satisfying this boundary condition.

We use the method of asymptotic expansions and conjecture that the solution $c$ has the form

$$
\begin{gathered}
c(w)=c_{0}+c_{1}\left(w-w^{*}\right)^{\alpha}+o\left(\left(w-w^{*}\right)^{\alpha}\right), \\
0<\alpha<1, \quad c_{1}>0 .
\end{gathered}
$$

The calculation proceeds in following steps: $(i)$ substitute the above trial form in to eq. (17), expand the resulting equation in powers of $w-w^{*}$, retaining terms with the lowest exponents, (ii) look for $\alpha \in(0,1)$ such that non-zero $c_{1}$ exist that makes the lowest order term in the expansion vanish. As a result, we find that $\alpha=1 / 2$ and

$$
c_{1}=\left.\sqrt{\frac{2}{\left|w^{*}\right|} \frac{-u^{\prime}(c) / u^{\prime \prime}(c)-\bar{u}^{\prime}(\bar{c}) / \bar{u}^{\prime \prime}(\bar{c})}{-u^{\prime \prime \prime}(c) / u^{\prime \prime}(c)-\bar{u}^{\prime \prime \prime}(\bar{c}) / \bar{u}^{\prime \prime}(\bar{c})}}\right|_{w=w^{*}} .
$$

This calculation has assumed that $c\left(w^{*}\right)=c_{0}>0$ but nothing about the utility function, other than its standard properties (monotonicity, concavity), that $u^{\prime \prime \prime}, \bar{u}^{\prime \prime \prime}$ are always non-zero (note that this rules out quadratic utilities), 
and that the expression under the square root in eq. (21) is positive.

Finally, we can find the asymptotic behaviour of $r$ and $w$. Back substituting the expansion of $c$, eq. (20), together with $\alpha=1 / 2$ and $c_{1}$ of eq. (21) into the expression for $r$, eq. (18), and again keeping only leading order terms, we recover eq. (13b) after some straight-forward algebra. To finally obtain the expansion for $f$, eq. (13c), one merely needs to substitute the $r$ expansion into the analytic solution for $f$, eq. (19). The interest rate term is obviously the leading order one, the integral in the exponential yields a logarithm, and we end up with the power law of eq. (13c). The asymptotic expansion cannot fix the overall normalisation of $f$, and hence we leave an undetermined coefficient $f_{0}$ in the expansion (the value could in principle be found from a numerical solution if needed).

\section{A.3 Time-dependent Fokker-Planck equation}

In order to compute the time-dependent distribution function $f(w, t)$, we need to solve the Fokker-Planck equation with time derivative term retained. Writing in terms of the probability current $j$, this reads

$$
\begin{gathered}
\partial_{t} f(w, t)=-\partial_{w} j(w, t), \\
j(w, t)=[a+r(w) w-c(w)] f(w, t)-\frac{1}{2} s^{2} \partial_{w} f(w, t) .
\end{gathered}
$$

This is to be solved with the boundary and initial conditions

$$
\begin{gathered}
\left.j(w, t)\right|_{\text {boundaries }}=0 \quad \forall t \\
f(w, 0)=f_{\text {init }}(w),
\end{gathered}
$$


where $f_{\text {init }}$ is some probability distribution function. It is easy to verify that a solution to eq. (22) exists in the form $f(w, t)=X_{\lambda}(w) T_{\lambda}(t)$, where $T(t)=\exp (-\lambda t)$ and $\lambda>0$ is a boundary condition dependent constant. Using well-known Sturm-Liouville theory, it can further be shown that the general solution to eq. (22) can be expressed as

$$
f(t, w)=\sum_{i=0}^{\infty} f_{i} \mathrm{e}^{-\lambda_{i} t} X_{\lambda_{i}}(w),
$$

where $X_{\lambda_{i}}, \lambda_{i}$ satisfy

$$
\begin{gathered}
\lambda_{i} X(w)=\left\{[a+r(w) w-c(w)] X(w)-\frac{1}{2} s^{2} X^{\prime}(w)\right\}^{\prime}, \\
\lambda_{i} \text { s.t. }\left.X_{\lambda_{i}}(w)\right|_{w=w^{*}, \bar{w}^{*}}=0, \quad \lambda_{i}>\lambda_{j} \quad \forall i>j
\end{gathered}
$$

and $f_{i}$ are constants such that initial condition 23b holds. In addition, $\lambda_{0}=0$ and $X_{0}(w)$ is the steady state distribution function. 


\section{References}

Tobias Adrian and Nina Boyarchenko. Interdiary Leverage Cycles and Financial Stability. 2013. URL http://www.newyorkfed.org/research/ staff_reports/sr567.pdf.

S Rao Aiyagari. Uninsured idiosyncratic risk and aggregate saving. The Quarterly Journal of Economics, 109(3):659-684, 1994. ISSN 0033-5533.

Robert J Barro and Xavier Sala-i Martin. Economic Growth. McGraw-Hill, 1995.

Olivier J Blanchard, Davide Furceri, and Andrea Pescatori. A prolonged period of low real interest rates? In Coen Teulings and Richard Baldwin, editors, Secular Stagnation: Facts, Causes and Cures, chapter 8, pages 101-110. Centre for Economic Policy Research, London, 2014.

Martin Browning and Annamaria Lusardi. Household saving: Micro theories and micro facts. Journal of Economic literature, pages 1797-1855, 1996. ISSN 0022-0515.

Markus K. Brunnermeier and Yuliy Sannikov. A Macroeconomic Model with a Financial Sector. American Economic Review, 104(2):379421, February 2014. ISSN 0002-8282. doi: 10.1257/aer.104.2. 379. URL http://wwW.ingentaconnect.com/content/aea/aer/2014/ $00000104 / 00000002 / \operatorname{art} 00002$.

Luigi Buttiglione, Philip Lane, Lucrezia Reichlin, and Vincent Reinhart. Deleveraging? What Deleveraging. 2014. URL http://www.cepr.org/ sites/default/files/news/Geneva16_0.pdf 
Ricardo J Caballero and Arvind Krishnamurthy. Global Imbalances and Financial Fragility. American Economic Review, 99(2):584-588, 2009. URL http://www. aeaweb.org/articles.php?doi=10.1257/aer.99.2.584.

Ricardo J Caballero, Emmanuel Farhi, and Pierre-Olivier Gourinchas. An Equilibrium Model of "Global Imbalances" and Low Interest Rates. American Economic Review, 98(1):358-393, 2008.

Christopher D Carroll. A theory of the consumption function, with and without liquidity constraints. Journal of Economic Perspectives, pages 23-45, 2001. ISSN 0895-3309.

Richard $\mathrm{H}$ Clarida. International lending and borrowing in a stochastic, stationary equilibrium. International Economic Review, pages 543-558, 1990. ISSN 0020-6598.

Angus Deaton and Christina Paxson. Intertemporal Choice and Inequality. The Journal of Political Economy, 102(3):437-467, 1994.

Gauti B Eggertsson and Neil R Mehrotra. A model of secular stagnation. 2014.

John Geanakoplos. The leverage cycle. In NBER Macroeconomics Annual 2009, Volume 24, pages 1-65. University of Chicago Press, 2009.

John Geanakoplos. Solving the present crisis and managing the leverage cycle. 2010.

Fatih Guvenen. Macroeconomics with hetereogeneity: a practical guide. Economic Quarterly, (3Q):255-326, 2011.

Zhiguo He and Arvind Krishnamurthy. Intermediary Asset Pricing. American Economic Review, 103(2):732-770, 2013. ISSN 0002-8282. 
John Heaton and Deborah Lucas. The importance of investor heterogeneity and financial market imperfections for the behavior of asset prices. In Carnegie-Rochester Conference Series on Public Policy, volume 42, pages 1-32. Elsevier, 1995. ISBN 0167-2231.

Mark Huggett. The risk-free rate in heterogeneous-agent incompleteinsurance economies. Journal of economic Dynamics and Control, 17(5): 953-969, 1993. ISSN 0165-1889.

IMF. Perspectives on Global Real Interest Rates. In World Economic Outlook, chapter 3. International Monetary Fund, Washington DC, april edition, 2014. URL https://www.imf.org/external/pubs/ft/weo/2014/ $01 / \mathrm{pdf} / \mathrm{c} 3 \cdot \mathrm{pdf}$

Jukka Isohätälä, Alistair Milne, and Donald Robertson. The net worth trap: investment and output dynamics in the presence of financing constraints. 2014 .

Elyès Jouini, Jean-Michel Marin, and Clotilde Napp. Discounting and divergence of opinion. Journal of Economic Theory, 145(2):830-859, 2010. ISSN 0022-0531.

Michael Magill and Martine Quinzii. Infinite horizon incomplete markets. Econometrica: Journal of the Econometric Society, pages 853-880, 1994. ISSN 0012-9682.

Michael Magill and Martine Quinzii. Theory of Incomplete Markets, Volume $1,1996$.

Michael Magill and Wayne Shafer. Incomplete markets. Handbook of mathematical economics, 4:1523-1614, 1991. ISSN 1573-4382. 
Costas Meghir and Luigi Pistaferri. Earnings, consumption and life cycle choices. Handbook of Labor Economics, 4:773-854, 2011. ISSN 1573-4463.

Rajnish Mehra and Edward C Prescott. The equity premium: A puzzle. Journal of monetary Economics, 15(2):145-161, 1985. ISSN 0304-3932.

Lloyd A Metzler. Wealth, saving, and the rate of interest. The Journal of Political Economy, pages 93-116, 1951. ISSN 0022-3808.

Alfio Quarteroni and Alberto Valli. Numerical approximation of partial differential equations, volume 23. Springer Science \& Business Media, 2008. ISBN 3540852670.

Eugen von Böhm-Bawerk. Capital and Interest: Positive theory of capital, volume 2. Libertarian Press, 1959.

Ludwig Von Mises. Theory of Money and Credit, The. Ludwig von Mises Institute, 1963. ISBN 1610163222. URL http://books .google.com/books? id=hHnIHlCm_CcC\&pgis=1. 